


\title{
WERTE DER DEUTSCHEN HEIMAT
}

Veröffentlichungen der Kommission für Heimatforschung

\author{
Band 5
}

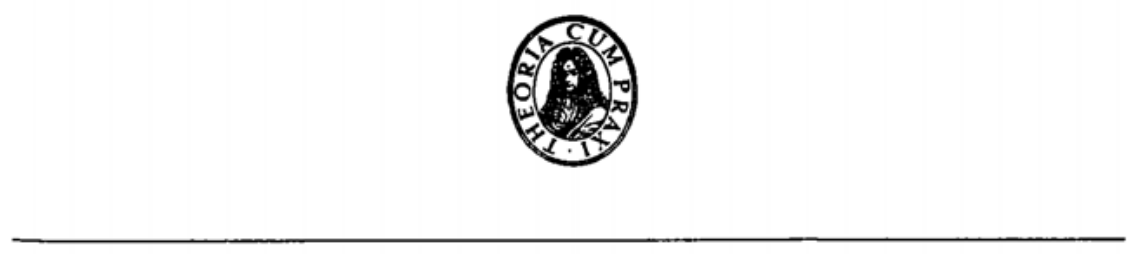

AKADEMIE-VERIAG - BERLIN 


\section{DAS \\ LIMBACHER LAND}

Ergebnisse der heimatkundlichen Bestandsaufnahme

im Gebiet von Limbach-Oberfrohna und Hohenstein-Ernstthal

Bearbeitet in der Arbeitsstelle Dresden

nach einem Grundmanuskript von Horst Strohbach

und einer Untersuchung zur Geschichte der Arbeiterbewegung

von Rudolph Strauß

Mit 31 Abbildungen, 8 Kunstdrucktafeln, 1 Ubersichtskarte

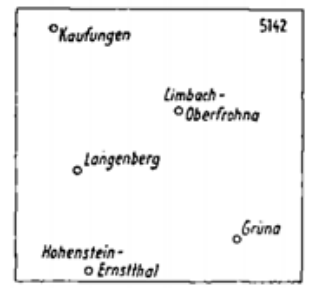


Erschienen in Akademie -Verlag GmbH, Berlin W 8, Leipziger Straße 3-4

Copyright 1962 by Akademie-Verlag $\mathrm{GmbH}$

Lizenz-Nr. 202 $\cdot$ 100/130/62

Kartengenehmigung: MdI der DDR Nr.: 6854

Gcsamtherstellung: Druckhaus „Maxim Gorki“, Altenburg

Bestellnummer : 2084/5 - ES 15 D 